\title{
In vitro evaluation of Panax notoginseng Rg1 released from collagen/chitosan-gelatin microsphere scaffolds for angiogenesis
}

\author{
Yurong Zheng ${ }^{1}$, Zhanzeng Feng ${ }^{1}$, Chuangang You${ }^{1}$, Yunyun $\mathrm{Jin}^{1}$, Xinlei $\mathrm{Hu}^{2}$, Xingang Wang ${ }^{1}$ and Chunmao Han ${ }^{1 *}$
}

* Correspondence:
hanchunmao1@126.com
'Department of Burns, Second
Affiliated Hospital of Zhejiang
University, School of Medicine,
Hangzhou 310009, China
Full list of author information is
available at the end of the article

() Biomed Central

\begin{abstract}
Background: The emergence of skin substitutes provides a new approach for the treatment of wound repair and healing. The consistent and steady release of angiogenic factors is an important factor in the promotion of angiogenesis in skin substitutes, which usually lack, yet need, a vascular network.

Methods: In this study, ginsenoside Rg1, a natural compound isolated from Panax notoginseng (PNS), was incorporated into a collagen/chitosan-gelatin microsphere (CC-GMS) scaffold. The cumulative release kinetics were evaluated, and the effects of the released Rg1 on human umbilical vein endothelial cells (HUVECS) behavior, including proliferation, migration, tube formation, cell-cycle progression, cell apoptosis, and vascular endothelial growth factor (VEGF) secretion, were investigated. Additionally, HUVECS were cultured on the CC-GMS scaffold to test its biocompatibility. Standard Rg1 and VEGF were used as positive controls.

Results: The results indicated that the CC-GMS scaffold had good release kinetics. The Rg1 released from the CC-GMS scaffold did not lose its activity and had a significant effect on HUVEC proliferation. Both Rg1 and VEGF promoted HUVEC migration and tube formation. Rg1 did not induce HUVEC apoptosis but instead promoted HUVEC progression into the $S$ and G2/M phases of the cell cycle. Rg1 significantly increased VEGF secretion compared with that in the control group. HUVEC culture on the CC-GMS scaffold indicated that this scaffold has good biocompatibility and that CC-GMS scaffolds containing different concentrations of Rg1 promote HUVEC attachment in a dose- and time-dependent manner.
\end{abstract}

Conclusions: $\mathrm{Rg} 1$ may represent a new class of angiogenic agent that can be encapsulated in CC-GMS scaffolds to exert angiogenic effects in engineered tissue.

Keywords: Angiogenesis, Panax notoginseng saponins, Gelatin microsphere, Controlled release, Vascular endothelial growth factor (VEGF)

\section{Background}

Skin loss remains a major healthcare problem around the world, especially in developing countries [1]. As such dermal defects do not heal spontaneously, scar formation due to full-thickness skin loss is inevitable unless skin substitutes are used [2]. The porous collagen/chitosan (CC) scaffold-based skin tissue engineering approach has become an important method for skin tissue repair and regeneration. Due to its natural origin, this scaffold has high biocompatibility and biodegradability. Implanted CC

(c) 2013 Zheng et al.; licensee BioMed Central Ltd. This is an Open Access article distributed under the terms of the Creative Commons Attribution License (http://creativecommons.org/licenses/by/2.0), which permits unrestricted use, distribution, and reproduction in any medium, provided the original work is properly cited. The Creative Commons Public Domain Dedication waiver (http://creativecommons.org/publicdomain/zero/1.0/) applies to the data made available in this article, unless otherwise stated. 
scaffolds could be used as a substrate for initial cell attachment and physical support for tissue guidance to accelerate wound healing in vivo [3,4]. However, a CC scaffold itself lacks normal vascular networks, and angiogenesis is slow after implantation in vivo. This scaffold may not be sufficient to induce rapid wound angiogenesis and regeneration at the initial stage of wound healing [5]. To accelerate angiogenesis, a CC scaffold could be combined with different types of microspheres as carriers for the controlled release of growth factors or other angiogenic factors. An extraordinary number of natural (i.e., collagen, alginate, and gelatin) and synthetic (i.e., poly(glycolic acid) and poly (L-lactic acid)) materials have been used as biomaterials in controlled-release applications [6]. Among these materials, gelatin, a natural polymer derived from collagen, is widely used. To load different bioactive factors, variations in the electrical and physical properties of gelatin microsphere (GMS)-based controlled-release systems can be achieved, depending on the fabrication method [7]. The combination of a GMS controlled drug delivery system with a skin tissue scaffold could be highly beneficial for wound angiogenesis and regeneration.

Angiogenic growth factors are often used in tissue engineering. However, growth factors have short biological half-lives. Platelet-derived growth factor (PDGF), isolated from platelets, cannot be detected in the circulation and has a half-life of less than $4 \mathrm{~h}$ when injected intravenously [8]. Moreover, the method of scaffold production and the surrounding in vivo environment may accelerate growth factor deactivation. Thus, there are limitations to maintaining therapeutic levels of growth factors at wound sites for healing periods of up to 2 weeks in the early period of angiogenesis.

Panax notoginseng (PNS), a well-known traditional Chinese medicine that has been extensively used for thousands of years, has been widely used in vitro and in vivo to encourage angiogenesis. Ginsenosides are the major active components of PNS. Ginsenoside Rg1, abundant in PNS, has a rigid steroidal skeleton with four transfused rings and two sugar moieties [9]. This ginsenoside is one of the most active ingredients in PNS and has a broad range of activities. Rg1 has estrogen-like activity and may represent a novel class of potent phytoestrogens [10]. Estrogen is known to directly modulate angiogenesis via effects on endothelial cells [11]. Rg1 has been demonstrated to have beneficial effects on ischemia-induced angiogenesis [12] and to enhance endothelial progenitor cell angiogenic potency [13]. These findings indicate the potential usefulness of ginsenoside Rg1 in angiogenesis and regeneration in skin tissue engineering.

Controlled release of Rg1 from a porous CC-GMS scaffold may be of effect in enhancing wound angiogenesis and healing. To date, there are few studies on Rg1 used in scaffolds, and the stability and activity of Rg1 remain unknown after its release from a CC-GMS scaffold. In this study, a porous CC-GMS scaffold for the controlled release of Rg1 was designed for angiogenesis and regeneration in skin tissue engineering. The Rg1 release kinetics were investigated. The activity of the released Rg1 was characterized by measuring human umbilical vein endothelial cells (HUVECs) proliferation, migration, tube formation, cell-cycle progression, apoptosis, and vascular endothelial growth factor (VEGF) expression. The optimum Rg1 concentration was also detected. Additionally, HUVECs were cultured on CC-GMS scaffolds to detect the scaffolds' biocompatibility. The purpose of this study was to develop a new CC-GMS scaffold that can slowly release Rg1 and to evaluate the activity and stability of the released Rg1. 


\section{Materials and methods Materials}

Rg1 (purity $>98 \%$ ) was purchased from the National Institute for the Control of Pharmaceutical and Biological Products (NICPBP, Beijing, China). A stock solution of Rg1 was prepared in sterile dimethyl sulfoxide (DMSO) (Sigma, Deisenhofen, Germany). VEGF and HUVECs were purchased from Life Technologies Corporation (Carlsbad, NM, USA). Medium 200 and Low Serum Growth Supplement (LSGS) were purchased from Invitrogen (Carlsbad, CA, USA). Fetal bovine serum was obtained from Gibco (Grand Island, NY, USA). An XTT Cell Proliferation Assay Kit (2, 3-bis-(2-methoxy-4-nitro-5-sulfophenyl)-2H-tetrazolium-5-carboxanilide), BD Matrigel ${ }^{\mathrm{Tw}}$, a cell cycle kit, and a cell apoptosis kit were purchased from BD Biosciences (San Diego, CA, US). Transwell-24 well permeable supports $(8.0 \mathrm{~mm})$ were obtained from Corning Life Sciences. An anti-VEGF antibody was purchased from Abcam (Cambridge, MA, USA). Goat anti-rabbit IgG-FITC was purchased from Pierce (Rockford, IL, USA). The reagent 4', 6-diamidino-2-phenylindole dihydrochloride (DAPI) was purchased from Sigma (St. Louis, MO, USA).

\section{Cell culture and seeding}

HUVECs were expanded in Medium 200 supplemented with $10 \mathrm{ml}$ of LSGS and used for experiments between passages 3 and 6 to ensure the genetic stability of the culture, according to the manufacturer's instructions. The HUVECs were expanded in flasks in Medium 200 and $1 \%$ penicillin/streptomycin in a humidified incubator at $37^{\circ} \mathrm{C}$ with $5 \%$ $\mathrm{CO}_{2}$. Every 3-4 days, the HUVECs were passaged with $0.05 \%$ trypsin, and the medium was changed every other day.

\section{Preparation of CC scaffolds activated with GMSs containing Rg1/VEGF}

Type A gelatin was used to fabricate GMSs following the method of emulsioncondensation cross-linking [14]. In brief, $5 \mathrm{ml}$ of a gelatin solution (10\%) and $100 \mathrm{ml}$ of soybean oil (preheated to $45^{\circ} \mathrm{C}$ ) were mixed together and stirred at 13,000 rpm for $10 \mathrm{~min}$ in a $45^{\circ} \mathrm{C}$ water bath. Ice water was then added while stirring to cool the gelatin solution and form microspheres. Next, the microspheres were washed with precooled acetone to remove residual soybean oil. The precipitated microspheres were then cross-linked with a $1 \%$ glutaraldehyde solution at $37^{\circ} \mathrm{C}$ for $2 \mathrm{~h}$, followed by the addition of glycine (Sigma) at room temperature for $30 \mathrm{~min}$. The synthetic GMSs were washed with distilled water several times and dried at $37^{\circ} \mathrm{C}$. The sizes and shapes of the microspheres were examined under a scanning electron microscope (SEM) (Philips XL30, Eindhoven, Netherlands). Microspheres with a diameter ranging from 10-50 $\mu \mathrm{m}$ were selected by sifting through mesh. The water content of the microspheres was calculated based on their volume variation after swelling in PBS at room temperature. The original Rg1 and VEGF solutions were diluted with distilled deionized water to a defined concentration. Incorporation of Rg1 or VEGF into the GMSs was achieved by adding one of the above solutions to $2 \mathrm{mg}$ of freeze-dried GMSs and incubating for $2 \mathrm{~h}$ at room temperature to allow the solution to be impregnated into the dried microspheres. The Rg1 or VEGF solution was completely absorbed into the microspheres because the solution volume was much less than that theoretically required for the equilibrated swelling of microspheres. As a control, 
$20 \mu \mathrm{l}$ of PBS was dropped onto $2 \mathrm{mg}$ of freeze-dried GMSs to prepare Rg1-free, empty GMSs.

CC-GMS scaffolds were prepared using the freezing and lyophilizing method, with moderate modifications [15]. Briefly, type I collagen and chitosan were each dissolved in $0.5 \mathrm{M}$ acetic acid to form $0.5 \%(\mathrm{w} / \mathrm{v})$ solutions that were mixed at a ratio of 9:1 (v/v). GMSs containing different concentrations of Rg1, PBS, or VEGF were then homogeneously blended with the mixed solution. The cross-linking agent, a $0.1 \%(\mathrm{w} / \mathrm{v})$ glutaraldehyde solution, was added, and the mixture was injected into a 12-well plate. The plates containing the scaffolds were frozen at $-80^{\circ} \mathrm{C}$ overnight and then lyophilized for $24 \mathrm{~h}$ to form porous CC-GMS scaffolds. The scaffolds were washed several times with PBS and distilled water and were further treated with $75 \%$ ethanol before use.

The cumulative Rg1 released from the CC-GMS scaffolds in vitro was analyzed using a UV spectrophotometer at a wavelength of $208 \mathrm{~nm}$, until release stopped. Finally, the released Rg1 was diluted to specific concentrations and then added to culture medium for further HUVEC culture experiments.

\section{In vitro study}

The chemotactic effects of Rg1 on HUVECs were tested both for Rg1 released from the CC-GMS scaffold and for a standard Rg1 solution.

\section{Cell viability assessment by XTT assay}

The viability of the cells was assessed by XTT assay. Briefly, HUVECs were seeded at a density of $1 \times 10^{4}$ cells/well in a 96-well plate and cultured for $24 \mathrm{~h}$. After cell attachment, low-serum culture medium (0.5\% FBS) with different doses of released $\mathrm{Rg} 1$ $(0-100 \mu \mathrm{g} / \mathrm{ml})$ or $50 \mu \mathrm{g} / \mathrm{ml}$ standard Rg1 were added and cultured for 24,48 , or $72 \mathrm{~h}$. Cells treated with $20 \mathrm{ng} / \mathrm{ml}$ VEGF served as positive control groups. Next, XTT solution was added to the wells $(50 \mu \mathrm{l} /$ well). After $4 \mathrm{~h}$ of incubation, the absorbance was measured with a microplate reader (Bio-Rad, Hercules, CA, USA) at $490 \mathrm{~nm}$. Three duplicate wells from at least three independent experiments were tested.

\section{Transwell migration}

The effect of Rg1 on HUVEC invasion was measured using a $6.5 \mathrm{~mm}$ Transwell tissue culture insert with an $8.0 \mu \mathrm{m}$ polycarbonate membrane and a 24-well companion plate. The upper side of the membrane was pre-coated with 1:50 (v/v) Matrigel. In total, $2 \times 10^{4}$ HUVECs were resuspended in low-serum medium $(200 \mu \mathrm{l})$ and seeded onto the culture inserts in triplicate. The inserts were then deposited into the 24-well companion plate along with $600 \mu \mathrm{l}$ of low-serum medium containing different concentrations of released $\operatorname{Rg} 1(0-100 \mu \mathrm{g} / \mathrm{ml})$, standard Rg1, or VEGF. Next, $24 \mathrm{~h}$ after HUVEC seeding, the inserts were removed, fixed in $20 \%$ ethanol, and then washed with PBS. Noninvasive cells on the upper surface of the membrane were removed. Cells that migrated to the bottom well through the porous membrane were stained with a $0.1 \%$ crystal violet solution for $20 \mathrm{~min}$, photographed at $100 \times$ magnification, and counted using Image-Pro Plus software (v.6.0; Media Cybernetics, Silver Spring, MD). The percent increase in migration in each experimental group was compared with migration in the control group. 
Tube formation assay and quantification

In total, $1 \times 10^{5}$ HUVECs were cultured in 48-well plates with a layer of $10 \mathrm{mg} / \mathrm{ml}$ Matrigel diluted with 1:1 (v/v) serum-free medium. The plates pre-coated with Matrigel were then incubated at $37^{\circ} \mathrm{C}$ for $60 \mathrm{~min}$. HUVEC suspensions were cultured in culture medium with different concentrations of released Rg1, standard Rg1, or VEGF. The plates were incubated for $8 \mathrm{~h}$ at $37^{\circ} \mathrm{C}$. Tubular structures were dyed with calcein-AM, photographed $(100 \times)$, and examined using Image J software (US National Institutes of Health, http://rsb.info.nih.gov/ij/). The percent of tube formation in each experimental group was compared with tube formation in the control group.

\section{Apoptosis determination by annexin V-FITC assay}

In brief, $5 \times 10^{5}$ cells/well were seeded onto six-well culture plates. After $24 \mathrm{~h}$ of cell attachment and $24 \mathrm{~h}$ of serum starvation, the cells were exposed to fresh medium with different concentrations of released Rg1, standard Rg1, or VEGF. After 24 h of culture, the cells were rinsed with PBS, trypsinized, and centrifuged for $5 \mathrm{~min}$ at 2,000 rpm. The cells were then resuspended in $500 \mu \mathrm{l}$ of Annexin V Binding Buffer, which was provided in the Annexin V-FITC Kit (KeyGEN, Beijing, China). Next, $5 \mu \mathrm{l}$ of annexin $\mathrm{V}$-FITC and $5 \mu \mathrm{l}$ of propidium iodide (PI) were added to the test tube. The cells were incubated at room temperature for $15 \mathrm{~min}$ and protected from light. The samples were then analyzed with a BD FACScan analyzer.

\section{Cell-cycle progression}

Cells were seeded onto six-well culture plates at a density of $5 \times 10^{5}$ cells/well. After $24 \mathrm{~h}$ of cell attachment and $24 \mathrm{~h}$ of serum starvation, different concentrations of released Rg1, standard Rg1, or VEGF were added to the culture medium for $24 \mathrm{~h}$. Both floating and attached cells were collected and fixed in $500 \mu \mathrm{l}$ of ice-cold $75 \%$ ethanol overnight and washed three times in PBS. The cells were then treated with $100 \mu \mathrm{l}$ of RNase $\mathrm{A}$ at $37^{\circ} \mathrm{C}$ for $30 \mathrm{~min}$, stained with $400 \mu \mathrm{l}$ of PI at $4^{\circ} \mathrm{C}$ for $30 \mathrm{~min}$, and stored in the dark. The fluorescence of PI in HUVECs was measured using a BD FACScan analyzer. The wavelength of laser excitation was set at $488 \mathrm{~nm}$, with an emission wavelength at $590 \mathrm{~nm}$. In total, 20,000 cells were analyzed for each group. The percentages of cells in the G0/G1 phase, S phase, and G2/M phase were counted using GraphPad Prism 5.0 software (GraphPad Prism Software, San Diego, CA, US).

\section{Immunocytofluorescence staining of VEGF}

Immunocytofluorescence (ICF) staining was performed to demonstrate VEGF expression in HUVECs. HUVECs were first cultured in 24-well plates. After $24 \mathrm{~h}$ of cell attachment, different concentrations of released Rg1, standard Rg1, or VEGF were added to the culture medium for $24 \mathrm{~h}$. The HUVECs were washed with PBS three times and fixed with $4 \%$ chilled paraformaldehyde for $20 \mathrm{~min}$. The HUVECs were washed three times in PBS, followed by a blocking step using 5\% bovine serum albumin (BSA) for 20 min. A mouse monoclonal anti-VEGF antibody was then added and incubated overnight, followed by incubation with FITC-conjugated goat anti-mouse IgG secondary antibody for $1 \mathrm{~h}$ at room temperature in the dark. Additionally, the cell nuclei were stained with DAPI for $30 \mathrm{~min}$ at room temperature in the dark. After all of the steps, the cells were observed and photographed using a fluorescence 
microscope (Leica, Germany). Images were acquired and processed using ImagePro Plus software [16].

\section{Cell culture on CC-GMS scaffolds}

Composite scaffolds for in vitro cell growth were sterilized by exposure to UV light for $30 \mathrm{~min}$ on each side. Aliquots of $20 \mu \mathrm{l}$ of HUVECs were seeded onto CC-GMS scaffolds containing different concentrations of Rg1 or VEGF at a density of $5 \times 10^{4}$ cells per scaffold. The scaffolds were left undisturbed in an incubator for $2 \mathrm{~h}$ at $37^{\circ} \mathrm{C}$ to allow cell attachment, after which an additional $1 \mathrm{ml}$ of low-FBS medium was added to each well. The cells were cultured for 7 days, and the medium was changed every 3 days. Afterward, the scaffolds were first washed with PBS three times and then were fixed in $4 \%$ paraformaldehyde overnight. After washing with PBS three times, the scaffolds were stained with $100 \mu \mathrm{g} / \mathrm{ml}$ DAPI for $30 \mathrm{~min}$ at $37^{\circ} \mathrm{C}$, followed by FITC staining for $20 \mathrm{~min}$. The scaffolds were then photographed using a laser scanning confocal microscope (Leica, Germany).

\section{Statistical analysis}

The data were expressed as the mean \pm standard deviation (SD) and were analyzed by one-way ANOVA and Tukey's tests to determine the level of significance. A p value < 0.05 was considered to be significant, and $\mathrm{p}<0.01$ was considered to be highly significant.

\section{Results}

\section{Fabrication of GMSs and CC-GMS scaffolds}

Figure 1 demonstrates the morphology of the GMSs and CC-GMS scaffolds. The GMSs were round, with diameters between 10 and $50 \mu \mathrm{m}$ (Additional file 1). The CC-GMS scaffold demonstrated a three-dimensional porous structure with a pore size of $110 \pm 12 \mu \mathrm{m}$ and a porosity of $92 \% \pm 0.4 \%$. The diameter of the CC-GMS scaffolds was approximately $2 \mathrm{~cm}$, with a thickness of $2 \pm 0.2 \mathrm{~mm}$. The CC-GMS scaffold possessed interconnected structures after the GMSs were distributed evenly. The degradation rate of GMS and CC-GMS scaffold were $21.67 \pm 3.05$ days and $23.33 \pm 1.52$ days respectively.

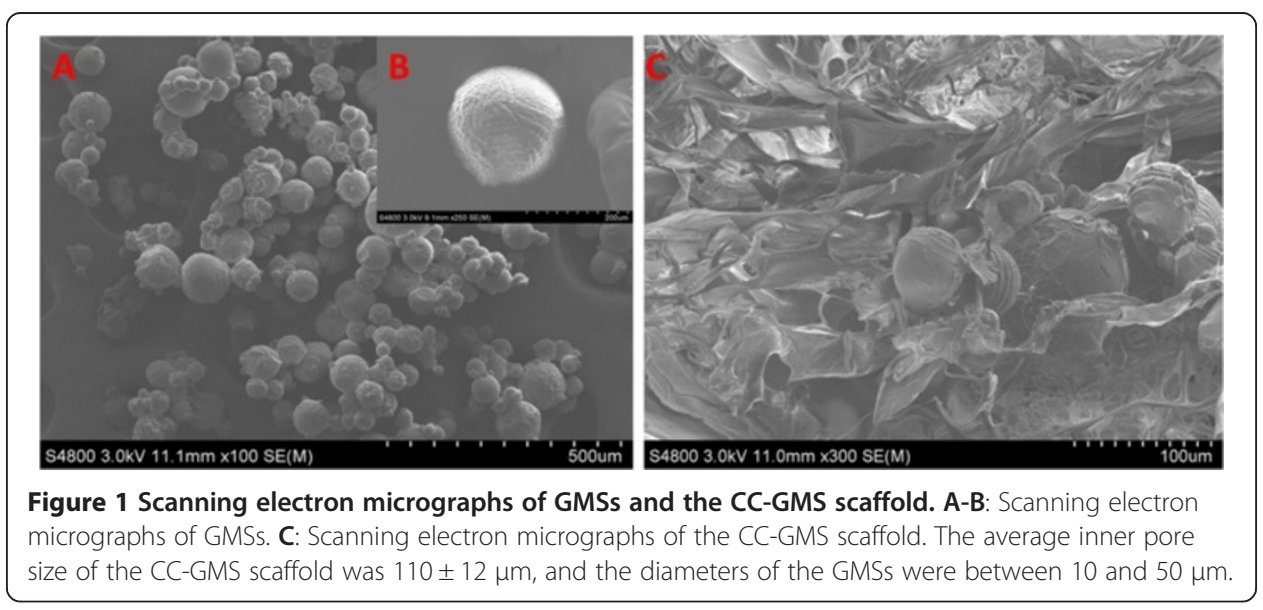




\section{Release of Rg1 from CC-GMS scaffold}

The cumulative Rg1 released from the CC-GMS scaffold and the GMSs is shown in Figure 2. Initial burst release was observed both from the CC-GMS scaffold and the GMSs during the first day, followed by slow release for up to 7 days, followed by a leveling off. The initial release of Rg1 (50, 100, or $200 \mu \mathrm{g}$ ) from the CC-GMS scaffold was $46 \%, 46.26 \%$, and $46.5 \%$, compared respectively with each total Rg1 dosage. The initial release of Rg1 (50 $\mu \mathrm{g}$ ) from the GMSs was 49.667\%. Then the amount released from both systems increased stably and slowly. After 7 days, the total release was $77.86 \%, 80.46 \%$, and $78.96 \%$, respectively from the CC-GMS scaffold and $83.27 \%$ from the GMSs. As the Rg1 loading content increased, the release rate increased correspondingly.

\section{Effects of Rg1 on HUVEC proliferation}

The loading of Rg1 into the CC-GMS scaffold may alter the activity of Rg1. In this study, chemotactic activity was measured to examine the stability and activity of the Rg1 that was released from the CC-GMS scaffold.

The effect of the released Rg1 on the proliferation of HUVECs was evaluated by XTT assay. As shown in Figure 3, Rg1 increased the proliferation of HUVECs in a dose- and time-dependent manner, with statistical significant proliferation observed at $50 \mu \mathrm{g} / \mathrm{ml}$ and at a time point of $72 \mathrm{~h}$, with proliferation in $267.59 \%$ of HUVECs. The proliferative effect of $50 \mu \mathrm{g} / \mathrm{ml}$ released Rg1 was slightly lower than the effect of VEGF (290.401\%) or $50 \mu \mathrm{g} / \mathrm{ml}$ standard $\mathrm{Rg} 1$ (281.085\%) but higher than the effect of $100 \mu \mathrm{g} / \mathrm{ml}$ released Rg1 (247.955\%).

\section{Effect of Rg1 on HUVEC migration}

The influence of the released $\operatorname{Rg} 1$ on HUVEC migration was determined by measuring the number of migrated cells, as shown in Figure 4. Compared with the control group,

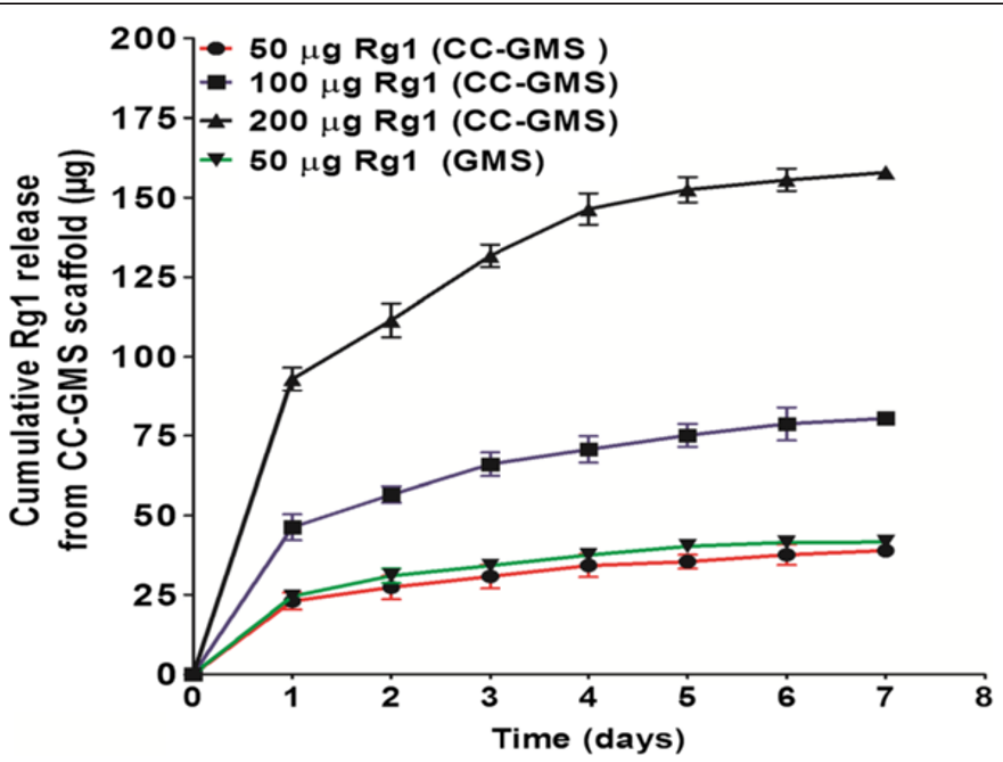

Figure $\mathbf{2}$ Release of Rg1 from the CC-GMS scaffold and GMS. The effects of loading content on Rg1

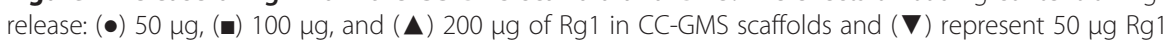
in GMS. 


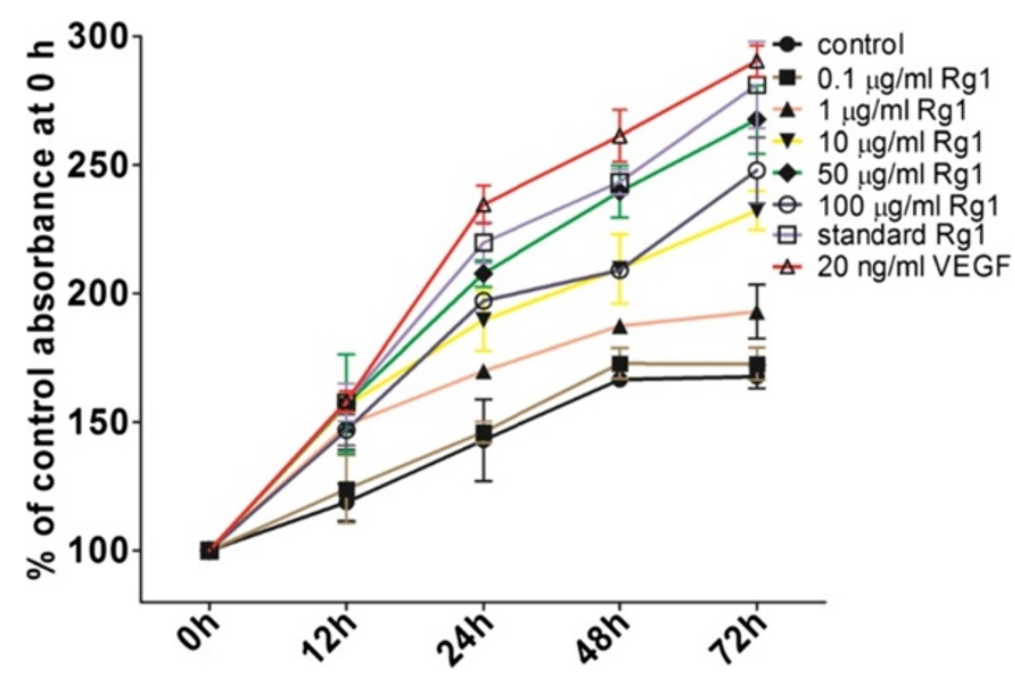

Figure 3 Effects of the released Rg1 on HUVEC proliferation. Cell proliferation was assessed using the XTT assay after $12,24,48$ or $72 \mathrm{~h}$ of treatment with different concentrations of released $\mathrm{Rg} 1,50 \mathrm{\mu g} / \mathrm{ml}$ standard Rg1, or $20 \mathrm{ng} / \mathrm{ml}$ VEGF. The results are expressed as the percent of cell proliferation compared with the control at $0 \mathrm{~h}$. The data are expressed as the mean $\pm \mathrm{SD}$ from three individual experiments. ${ }^{*} p<0.05$ compared with the control group.
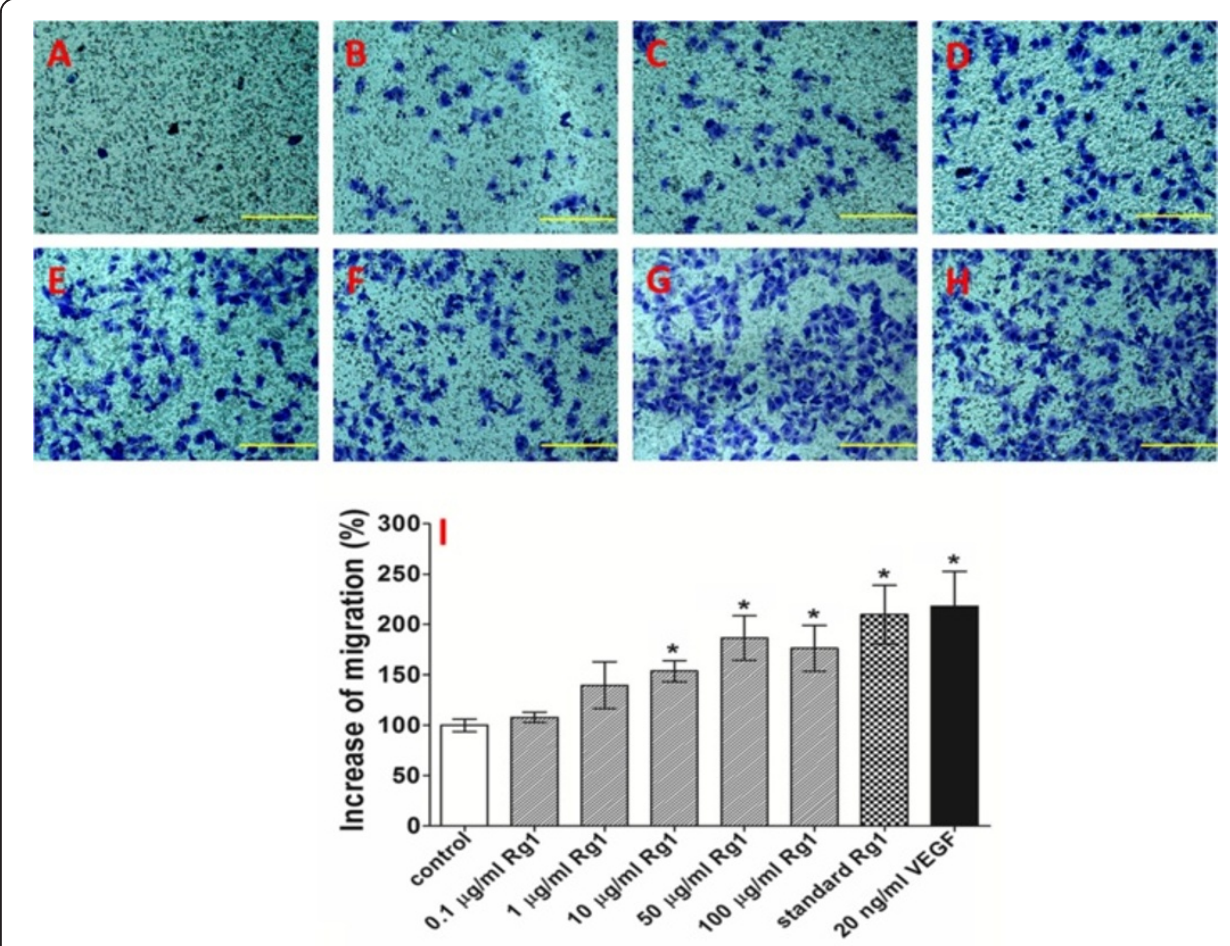

Figure 4 Effect of the released Rg1 on HUVEC migration. Observation of the effect of the released $\mathrm{Rg} 1$ on HUVEC migration after $24 \mathrm{~h}$ using a Transwell culture insert. A: Control group (untreated); B: $0.1 \mathrm{\mu g} / \mathrm{ml}$ released Rg1; C: $1 \mu \mathrm{g} / \mathrm{ml}$ released Rg1; D: $10 \mu \mathrm{g} / \mathrm{ml}$ released $\mathrm{Rg} 1 ; \mathbf{E}: 50 \mu \mathrm{g} / \mathrm{ml}$ released $\mathrm{Rg} 1 ; \mathbf{F}: 100 \mu \mathrm{g} / \mathrm{ml}$ released Rg1; G: $50 \mu \mathrm{g} / \mathrm{ml}$ standard Rg1; and $\mathbf{H}: 20 \mathrm{ng} / \mathrm{ml}$ VEGF. I: The percentage increase in HUVEC migration was compared with migration in the control group (untreated). Photographed by microscope at $200 \times$. The data are expressed as the mean \pm SD. Significant differences compared with controls are presented $\left({ }^{*} p<0.05\right)$. 
the released $\operatorname{Rg} 1$ groups showed a dose-dependent increase in the migration of HUVECs. Rg1 reached a maximum effect at a concentration of $50 \mu \mathrm{g} / \mathrm{ml}$ (Figure 4I). When the concentration reached $100 \mu \mathrm{g} / \mathrm{ml}$, the migrated cell number did not increase. VEGF at $20 \mathrm{ng} / \mathrm{ml}$ had a 14.6\% greater pro-migration effect than did $50 \mu \mathrm{g} / \mathrm{ml} \mathrm{Rg} 1$. Meanwhile, the released $\mathrm{Rg} 1$ at $50 \mu \mathrm{g} / \mathrm{ml}$ showed little decrease (11.1\%) compared with $50 \mu \mathrm{g} / \mathrm{ml}$ standard Rg1. There was no statistical difference between the $50 \mu \mathrm{g} / \mathrm{ml}$ standard Rg1 group and the VEGF group regarding HUVEC migration.

\section{Effect of Rg1 on Matrigel-induced tube formation}

To test the effect of the released Rg1 on HUVEC tube formation, a Matrigel model was used in this study. HUVECs did not form tubes, at least at a seeding density of 50,000 cells per well. As shown in Figure 5, the number of branching points was counted and then compared with that of the control group. The released Rg1, the standard Rg1, and VEGF all triggered significant increases in the number of elongated and robust tubelike structures. The released Rg1 induced cell tube formation in a dose-dependent manner, and the most effective concentration was $50 \mu \mathrm{g} / \mathrm{ml}$. When the $\operatorname{Rg} 1$ concentration was above $1 \mu \mathrm{g} / \mathrm{ml}$, the stimulation was found to be statistically significant compared with that of the blank control $(\mathrm{p}<0.05)$. The standard $\operatorname{Rg} 1$ group exhibited $6.18 \%$ lower activity than did the VEGF group. However, the remaining activity of $50 \mu \mathrm{g} / \mathrm{ml}$ released $\mathrm{Rg} 1$ remained approximately the same as that of standard $\operatorname{Rg} 1$.

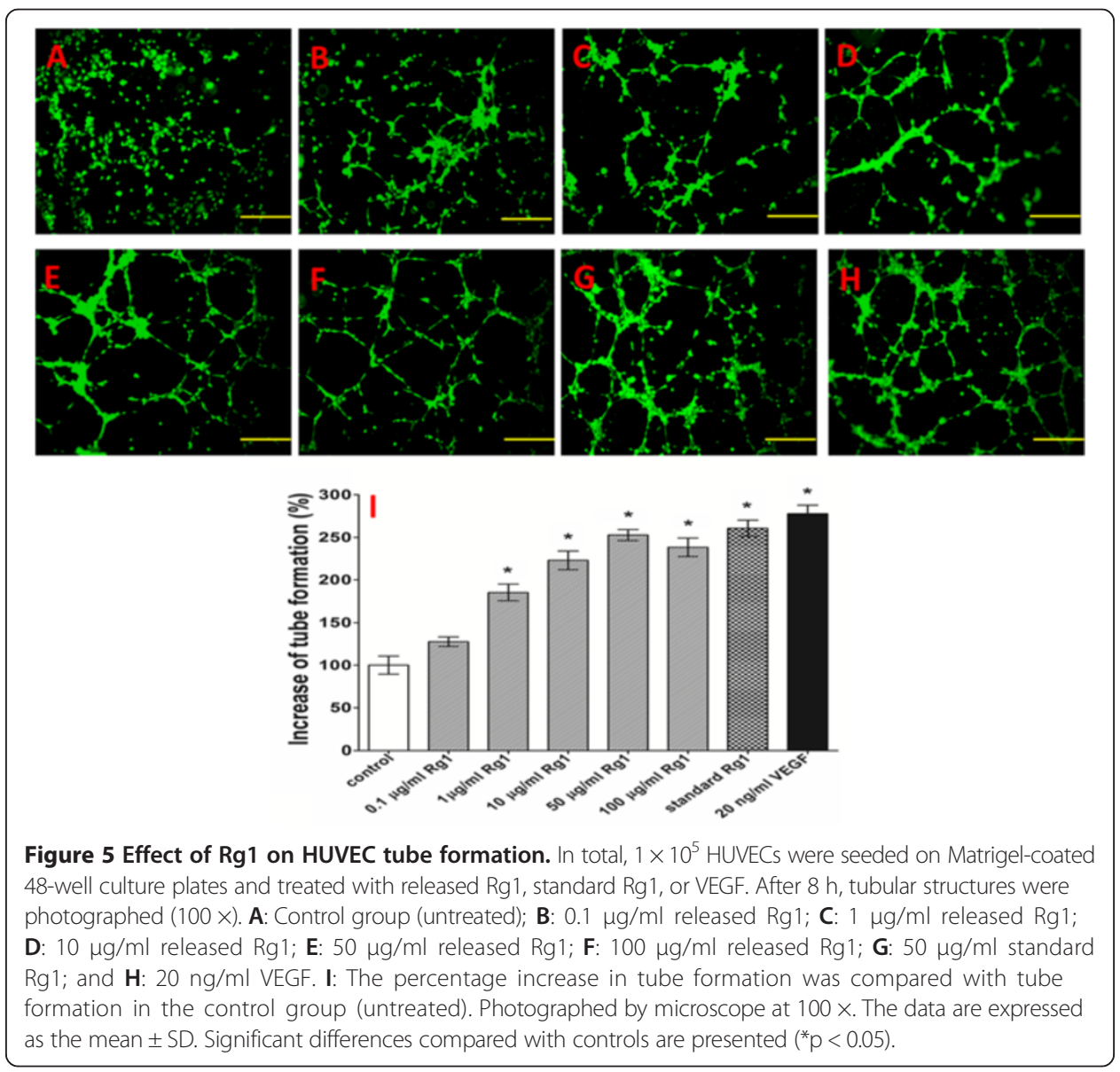




\section{Cell cycle and apoptosis analysis}

To determine the effect of the released Rg1 on the HUVECs' cell cycle, a cell cycle analysis was performed. Incubation with either Rg1 or VEGF resulted in increased cellcycle progression (Figure 6). Rg1 significantly increased the number of HUVECs in the proliferative phase ( $\mathrm{S}$ and $\mathrm{G} 2 / \mathrm{M}$ phases) and decreased the number in the resting phase (G0/G1 phase) in a dose-dependent manner. The control group displayed a low percentage of proliferation (S phase, $12.78 \%$, and $\mathrm{G} 2 / \mathrm{M}$ phase, $2.84 \%$ ), whereas the percentage of cells in the $\mathrm{S}$ phase increased to $30.23 \%$ and in the G2/M phase increased to 14.46\% with $50 \mu \mathrm{g} / \mathrm{ml} \operatorname{Rg} 1$ treatment. Compared with 1, 10 and $100 \mu \mathrm{g} / \mathrm{ml} \operatorname{Rg} 1$ group, $50 \mu \mathrm{g} / \mathrm{ml} \mathrm{Rg1}$ group had statistical significant differences both in $\mathrm{S}$ phase and G2/M phase. In the VEGF group, 30.94\% of cells were in the $S$ phase, and $17.69 \%$ were in the G2/M phase. There was no statistical difference between $50 \mu \mathrm{g} / \mathrm{ml}$ Rg1 group and VEGF group. The standard Rg1 group showed a similar effect as the $50 \mu \mathrm{g} / \mathrm{ml}$ released Rg1 group, with $28.45 \%$ cells in the $S$ phase and $18.02 \%$ in the G2/M phase. These data suggest that Rg1 induces cell proliferation by increasing the proportion of cells in the $\mathrm{S}$ and $\mathrm{G} 2 / \mathrm{M}$ phases and that the released Rg1 did not lose its activity.

Annexin V-FITC/PI staining was used to determine the extent of HUVEC apoptosis. As shown in Figure 7, the released Rg1 groups, the VEGF group, and the standard Rg1

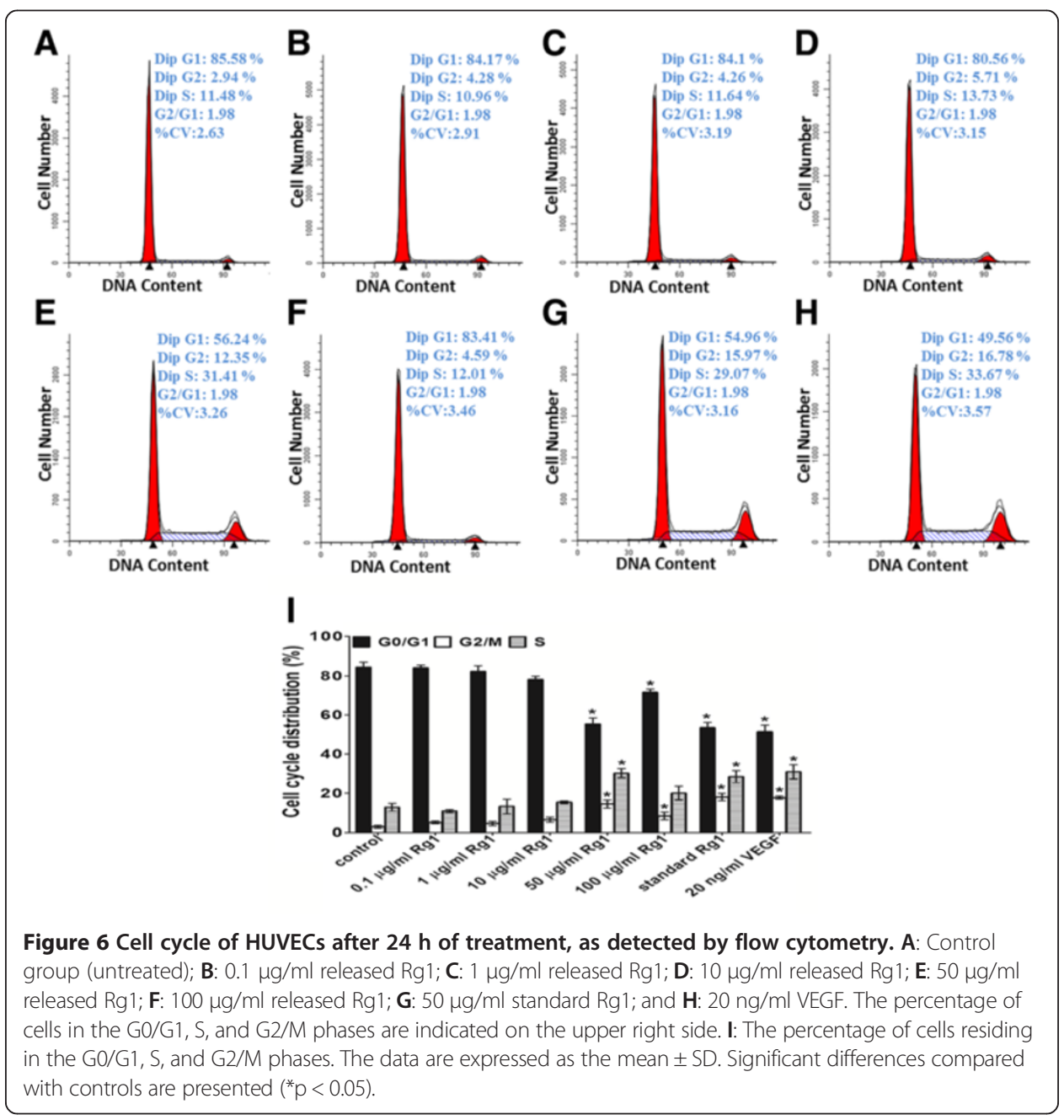




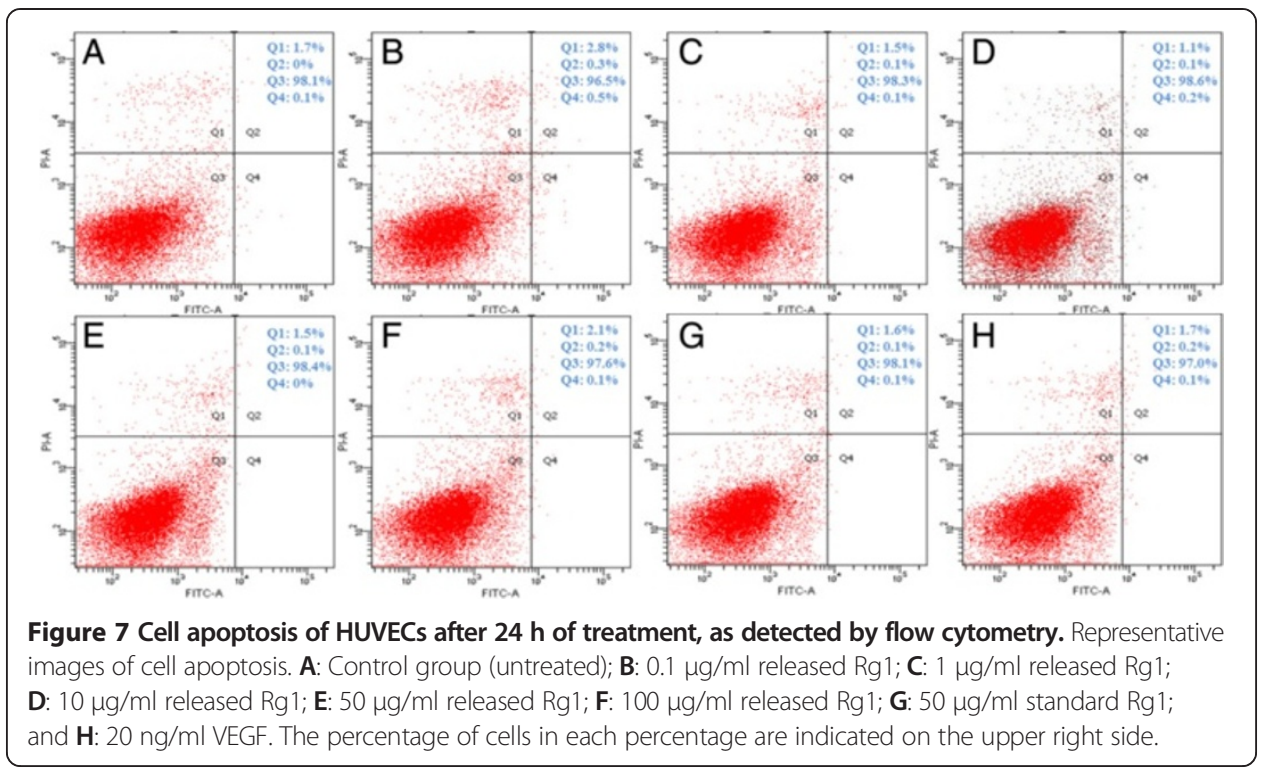

group did not show an increase in the apoptosis of HUVECs. There were few annexin V-FITC- and PI-positive cells. These results demonstrate that Rg1 has little toxicity toward HUVECs at the tested concentrations and that CC-GMS scaffold degradation did not increase the toxicity of the released Rg1.

\section{Effect on VEGF expression}

The expression of VEGF, which normally creates new blood vessels, was further assessed by an ICF assay after $24 \mathrm{~h}$ of incubation. As shown in Figure 8 , both $\operatorname{Rg} 1$ and VEGF caused an increase in VEGF expression, and the VEGF expression of HUVECs increased along with the increase in the released Rg1 concentration. In the $50 \mu \mathrm{g} / \mathrm{ml}$ Rg1 group, the VEGF expression was most significant, at approximately 4.18 times of the expression in the control group. The VEGF expression of the VEGF group and the standard Rg1 group was 4.38 and 4.20 times of the control group's expression, respectively. Compared with standard Rg1, the released $\mathrm{Rg} 1$ at $50 \mu \mathrm{g} / \mathrm{ml}$ showed a similar effect on VEGF expression. These findings demonstrated that Rg1 can induce VEGF expression, which is of great importance in the early stage of angiogenesis.

\section{HUVEC proliferation on CC-GMS scaffold}

Figure 9 shows laser scanning confocal microscopy (LSCM) images of proliferated HUVECs on the Rg1-loaded CC-GMS scaffold after 7 days of cultivation. The scaffold was brittle in its dried state but provided good malleability after being wetted with culture medium. The HUVECs were well attached and proliferated in a multilayered phase over the CC-GMS scaffold. Compared with proliferation in the vehicle group, enhanced HUVEC proliferation was observed within both the Rg1- and the VEGF-loaded CC-GMS scaffolds. Moreover, after 7 days of cultivation, the $50 \mu \mathrm{g} / \mathrm{ml}$ Rg1 group showed $18.84 \%$ more HUVEC proliferation than did the VEGF group. These results demonstrated that the porous CC-GMS scaffold could be utilized as a skin tissue substitute with the ability to regulate $\operatorname{Rg} 1$ release and the potential to increase cellular growth. 


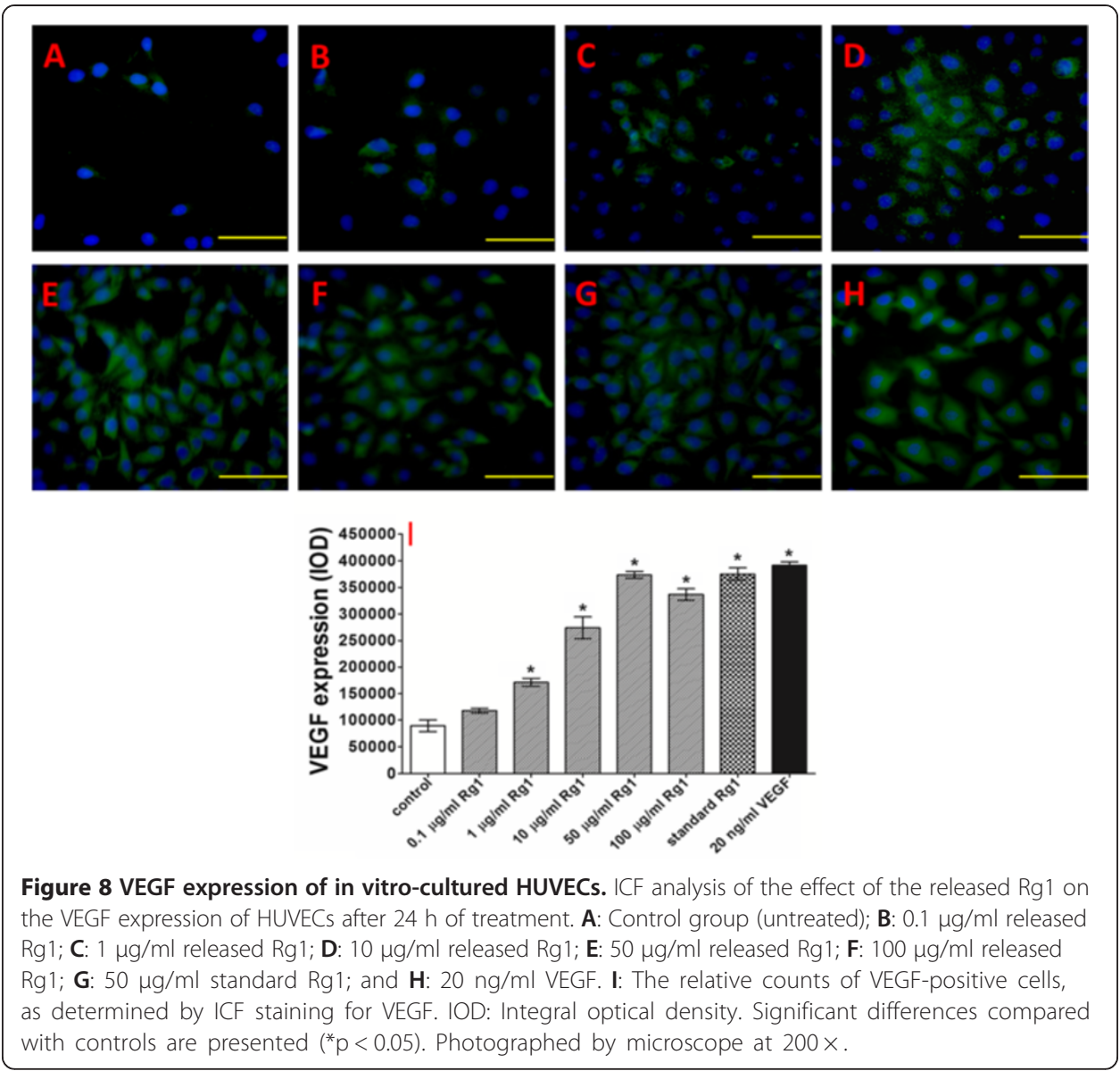

\section{Discussion}

VEGF is an endothelial cell-specific mitogen and an angiogenesis inducer. VEGF promotes the growth of vascular endothelial cells from the arteries, veins, and lymphatics [17]. VEGF is also a survival factor for endothelial cells, as it prevents the endothelial apoptosis induced by serum starvation. This prevention is achieved by mediating the phosphatidylinositol 3-kinase (PI3K)/Akt pathway [18] and inducing expression of the anti-apoptotic proteins Bcl-2, A1, XIAP, and survivin in endothelial cells [19,20]. As a functional ligand of the glucocorticoid receptor (GR), Rg1 has been shown to increase the phosphorylation of GR and the activities of PI3K, Akt/protein kinase B, and eNOS in HUVECs [21]. PI3K/Akt signaling has been found to be significantly important in HUVEC growth, survival, protein synthesis, and angiogenesis [22]. Consistent with this pathway, similar to VEGF, standard Rg1 at $50 \mu \mathrm{g} / \mathrm{ml}$ stimulated significant HUVEC proliferation, migration, and tube formation, with increases of $267.59 \%$ (72 h), 186.42\%, and $252.73 \%$, respectively, compared with the vehicle control group. This finding is in accordance with reports that Rg1 promotes HUVEC proliferation, migration, and tube formation [23].

Moreover, as expected, both Rg1 and VEGF promoted HUVEC transition from G0/G1 to G2/M. Treatment of HUVECs with standard Rg1 or VEGF for $24 \mathrm{~h}$ induced a significant percentage of cells to enter the S and G2/M phases (28.45\% and $30.94 \%$, respectively, in the S phase and $18.02 \%$ and $17.69 \%$, respectively, in the G2/M phase) compared with 


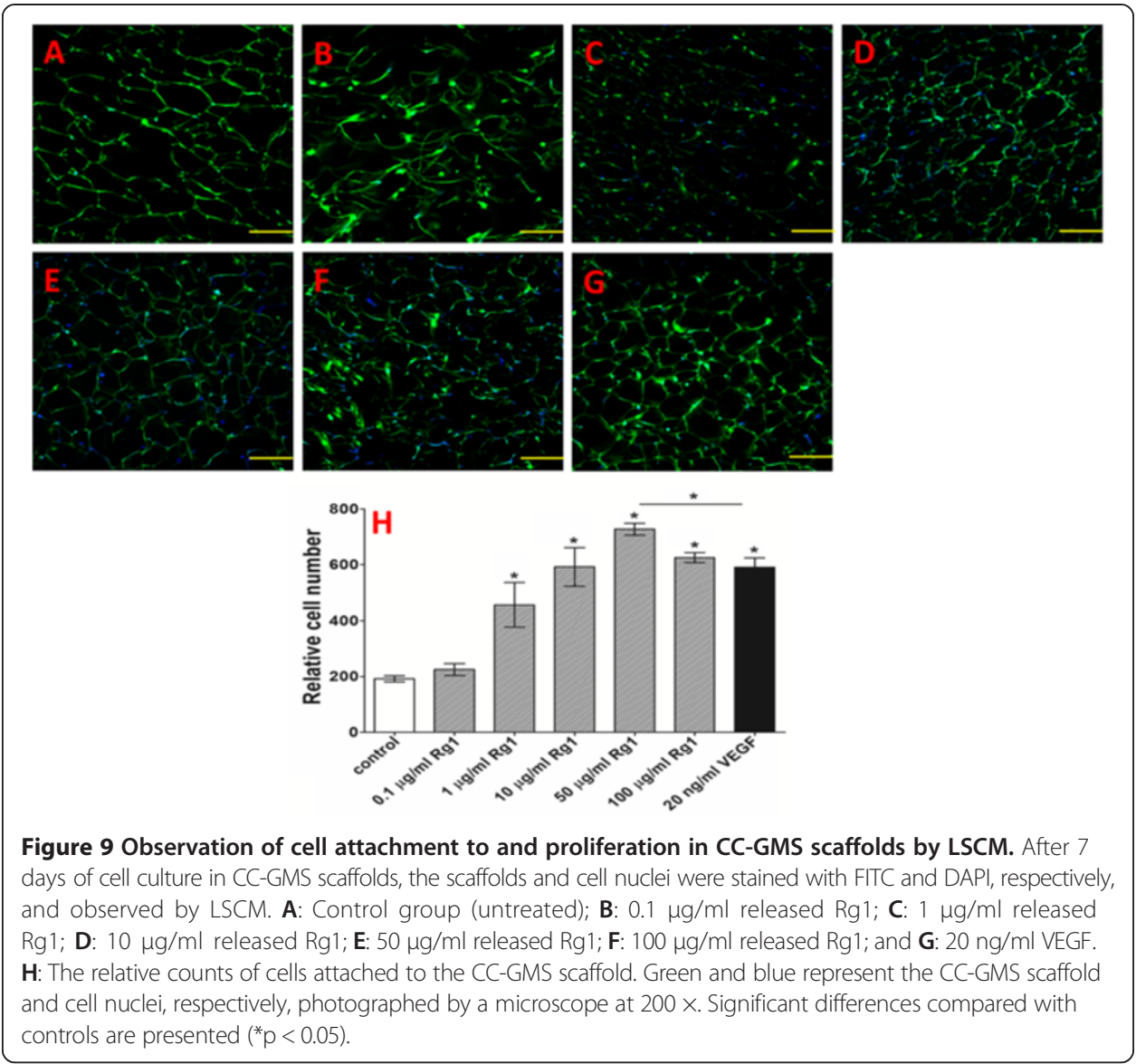

the control (12.78\% in the S phase and $2.84 \%$ in the G2/M phase; Figure 6). Additionally, after $24 \mathrm{~h}$ of treatment, $\operatorname{Rg} 1$ did not increase the proportion of apoptotic cells (Figure 7), and all of the groups were similar. In support of our data, it has been reported that the activation of PI3K and PKB leads to FOXO3a phosphorylation and sequestration in the cytoplasm, thereby reducing growth arrest and DNA damage-inducible 45a expression, thus activating G2/M progression [24].

Because VEGF is known to be a key activator of angiogenesis, we examined whether Rg1 could upregulate VEGF production. We found that VEGF production was significantly elevated in response to Rg1 stimulation, as determined by an ICF assay (Figure 8). In support of our data, Rg1 has been reported to be a potent stimulator of VEGF expression in HUVECs, and importantly, this induction is mediated through a PI3K/Aktand $\beta$-catenin/T-cell factor-dependent pathway via the GR [25]. These results suggest that Rg1 promotes HUVEC survival, proliferation, migration, tube formation, cell-cycle progression, and VEGF expression and that these effects are dependent on the PI3K/ Akt pathway.

In this study, GMSs were used as carriers. The GMS release rate could be controlled by various cross-linking conditions, including the cross-linking agent type, density, and reaction period [26]. The cross-linking conditions were $1 \%$ glutaraldehyde solution at $37^{\circ} \mathrm{C}$ for $2 \mathrm{~h}$. Under these conditions, the initial burst release of $\mathrm{Rg} 1$ was approximately $46 \%$ (Figure 2). Rapid release at the initial step and maintenance of a proper concentration at the local site are favorable for bioreagent delivery [27]. The sustained release test 
in this study (Figure 2) clearly demonstrated that Rg1 was gradually released from the Rg1-impregnated CC-GMS scaffold. Moreover, the release rate of Rg1 from the CCGMS scaffold varied with the loading content. The release rate increased proportionally as the loading content increased. An initial Rg1 burst release may properly induce HUVEC attachment and proliferation, and the following steady release of Rg1 efficiently stimulates HUVEC migration and tube formation, thus leading to vascular structure formation. Incorporation of GMSs into the CC-GMS scaffold was thus required to attain steady Rg1 release.

Ginsenoside Rg1 consists of a gonane steroid nucleus and has 17 carbon atoms arranged in four rings [28]. The specific chemical structure of Rg1 consists of a high degree of ring structure, which makes its flexibility very limited. The ring structure is known to be inherently stable [29]. The Rg1 released from the CC-GMS scaffold showed nearly the same tube formation activity (96.06\%) as did the standard Rg1 solution. This result revealed that the Rg1 in the CC-GMS scaffold maintained its biological activity and that the fabrication procedure did not affect the stability of Rg1. In addition, the effect of the Rg1 released from the CC-GMS scaffold showed that Rg1 exerts its effect in a dose-dependent manner. Additionally, the concentration of $\operatorname{Rg} 1$ $(50 \mu \mathrm{g} / \mathrm{ml})$ used in this study is the optimal stimulatory dose for HUVECs, with responses slightly decreasing at higher doses. This phenomenon may be due to the effect of the cytotoxicity of ginsenoside $\operatorname{Rg} 1$ when the concentration is increased to $100 \mu \mathrm{g} / \mathrm{ml}$. Additionally, the above results revealed that the release rate of $\operatorname{Rg} 1$ can be controlled by varying the initial loading content of Rg1 to attain optimal therapeutic efficacy for wound tissue regeneration.

The Rg1-loaded CC-GMS scaffold induced significantly high cell attachment and proliferation, which indicated good cellular adaptability. Steady stimulation by the Rg1 from the CC-GMS scaffold might cause rapid cell proliferation within the scaffold. At 7 days after HUVEC culture on the CC-GMS scaffold, the Rg1-mediated effect on HUVEC attachment was approximately $18.84 \%$ higher than the effect of VEGF (Figure 9). These results indicated that the chemical stability of Rg1 was significantly better than that of VEGF. It is known that proteins are often unstable outside their native environments. The occurrence of protein denaturation may be attributed to a variety of factors, such as $\mathrm{pH}$, buffer species, and temperature. The half-life of VEGF was less than $10 \mathrm{~h}$. In contrast, the activities of Rg1 remained approximately the same. These results demonstrated that the CC-GMS scaffold can be utilized as a skin tissue substitute material with the ability to regulate Rg1 release and the potential to stimulate cellular growth. It is anticipated that different types of cells will freely migrate into Rg1-loaded CC-GMS scaffolds when applied to a skin defect to improve skin tissue angiogenesis and regeneration efficacy.

\section{Conclusion}

Rg1-loaded CC-GMS scaffolds may control Rg1 release, serve as a physical scaffold for cell proliferation, and promote angiogenesis. The $\operatorname{Rg} 1$ in the scaffold retained its biological activity, and the Rg1 released from the CC-GMS scaffold enhanced HUVEC proliferation, migration, tube formation, cell-cycle progression, and VEGF expression. The Rg1-loaded CC-GMS scaffold might be a valuable modality in skin tissue engineering-based angiogenesis and regenerative therapy. 


\title{
Additional file
}

Additional file 1: Figure S1. Micrographs of GMSs at $100 \times$.

\author{
Abbreviations \\ PNS: Panax notoginseng; CC-GMS: Collagen/chitosan-gelatin microsphere; HUVECs: Human umbilical vein endothelial \\ cells; VEGF: Vascular endothelial growth factor; CC: Collagen/chitosan; GMS: Gelatin microsphere; PDGF: Platelet-derived \\ growth factor; NICPBP: National Institute for the Control of Pharmaceutical and Biological Products; DMSO: Dimethyl \\ sulfoxide; LSGS: Low serum growth supplement; XTT: 2, 3-bis-(2-methoxy-4-nitro-5-sulfophenyl)-2H-tetrazolium-5- \\ carboxanilide; DAPI: 4', 6-diamidino-2-phenylindole dihydrochloride; SEM: Scanning electron microscope; \\ ICF: Immunocytofluorescence; BSA: Bovine serum albumin; LSCM: Laser scanning confocal microscopy; \\ PI3K: Phosphatidylinositol 3-kinase; GR: Glucocorticoid receptor.
}

\section{Competing interests}

The authors declare that they have no competing interests.

\section{Authors' contributions}

YZ and ZF carried out the in vitro experiments and drafted the manuscript. CY carried out the scanning electron microscope examination. YJ participated in the immunocytofluorescence staining. XH and XW participated in the design of the study and performed the statistical analysis. $\mathrm{CH}$ conceived of the study, and participated in its design and coordination and helped to draft the manuscript. All authors read and approved the final manuscript.

\section{Acknowledgements}

This work was financially supported by the Grand Science and Technology Special program of Zhejiang (2007C13040), the Natural Science Foundation of Zhejiang (LQ12H15001), and the Natural Science Foundation of China (81272120).

\section{Author details}

${ }^{1}$ Department of Burns, Second Affiliated Hospital of Zhejiang University, School of Medicine, Hangzhou 310009, China. 2Department of Orthopedics, Second Affiliated Hospital of Zhejiang University, College of Medicine, Binjiang Branch, Hangzhou 310000, China.

Received: 26 October 2013 Accepted: 26 December 2013

Published: 31 December 2013

\section{References}

1. MacNeil S: Progress and opportunities for tissue-engineered skin. Nature 2007, 445(7130):874-880.

2. Ma L, Gao C, Mao Z, Zhou J, Shen J, Hu X, Han C: Collagen/chitosan porous scaffolds with improved biostability for skin tissue engineering. Biomaterials 2003, 24(26):4833-4841.

3. Hutmacher DW: Scaffold design and fabrication technologies for engineering tissues — state of the art and future perspectives. J Biomater Sci Polym Ed 2001, 12(1):107-124.

4. Haifei S, Xingang W, Shoucheng W, Zhengwei M, Chuangang Y, Chunmao H: The effect of collagen-chitosan porous scaffold thickness on dermal regeneration in a one-stage grafting procedure. J Mech Behav Biomed Mater 2014, 29:114-125.

5. Chung JY, Kowal-Vern A, Latenser BA, Lewis RW 2nd: Cement-related injuries: review of a series, the National Burn Repository, and the prevailing literature. J Burn Care Res 2007, 28(6):827-834.

6. Patel ZS, Mikos AG: Angiogenesis with biomaterial-based drug-and cell-delivery systems. J Biomater Sci Polym Ed 2004, 15(6):701-726.

7. Young S, Wong M, Tabata Y, Mikos AG: Gelatin as a delivery vehicle for the controlled release of bioactive molecules. J Control Release 2005, 109(1):256-274.

8. Bowen-Pope DF, Malpass TW, Foster DM, Ross R: Platelet-derived growth factor in vivo: levels, activity, and rate of clearance. Blood 1984, 64(2):458-469.

9. Ling C, Li Y, Zhu X, Zhang C, Li M: Ginsenosides may reverse the dexamethasone-induced down-regulation of glucocorticoid receptor. Gen Comp Endocrinol 2005, 140(3):203-209.

10. Chan RY, Chen W-F, Dong A, Guo D, Wong M-S: Estrogen-like activity of ginsenoside Rg1 derived from Panax notoginseng. J Clin Endocrinol Metab 2002, 87(8):3691-3695.

11. Morales DE, McGowan KA, Grant DS, Maheshwari S, Bhartiya D, Cid MC, Kleinman HK, Schnaper HW: Estrogen promotes angiogenic activity in human umbilical vein endothelial cells in vitro and in a murine model. Circulation 1995, 91(3):755-763.

12. Yang N, Chen P, Tao Z, Zhou N, Gong X, Xu Z, Zhang M, Zhang D, Chen B, Tao Z: Beneficial effects of ginsenoside-Rg1 on ischemia-induced angiogenesis in diabetic mice. Acta Biochim Biophys Sin (Shanghai) 2012, 44(12):999-1005

13. Shi A, Gu N, Liu X, Wang X, Peng Y: Ginsenoside rg1 enhances endothelial progenitor cell angiogenic potency and prevents senescence in vitro. J Int Med Res 2011, 39(4):1306-1318.

14. Hiraoka Y, Yamashiro H, Yasuda K, Kimura Y, Inamoto T, Tabata Y: In situ regeneration of adipose tissue in rat fat pad by combining a collagen scaffold with gelatin microspheres containing basic fibroblast growth factor. Tissue Eng 2006, 12(6):1475-1487.

15. Shi H, Han C, Mao Z, Ma L, Gao C: Enhanced angiogenesis in porous collagen-chitosan scaffolds loaded with angiogenin. Tissue Eng Part A 2008, 14(11):1775-1785. 
16. Wu CC, Chen WH, Zao B, Lai PL, Lin TC, Lo HY, Shieh YH, Wu CH, Deng WP: Regenerative potentials of plateletrich plasma enhanced by collagen in retrieving pro-inflammatory cytokine-inhibited chondrogenesis. Biomaterials 2011, 32(25):5847-5854.

17. Ferrara N: Vascular endothelial growth factor: basic science and clinical progress. Endocr Rev 2004, 25(4):581-611.

18. Gerber H, McMurtrey A, Kowalski J, Yan M, Keyt B, Dixit V, Ferrara N: VEGF regulates endothelial cell survival by the PI3-kinase/Akt signal transduction pathway. Requirement for Flk-1/KDR activation. J Biol Chem 1998, 273(30)):336-343.

19. Tran J, Master Z, Joanne LY, Rak J, Dumont DJ, Kerbel RS: A role for survivin in chemoresistance of endothelial cells mediated by VEGF. Proc Natl Acad Sci 2002, 99(7):4349-4354.

20. Gerber H-P, Dixit V, Ferrara N: Vascular endothelial growth factor induces expression of the antiapoptotic proteins Bcl-2 and A1 in vascular endothelial cells. J Biol Chem 1998, 273(21):13313-13316.

21. Leung KW, Cheng Y-K, Mak NK, Chan KK, David Fan T, Wong RN: Signaling pathway of ginsenoside-Rg1 leading to nitric oxide production in endothelial cells. FEBS Lett 2006, 580(13):3211-3216.

22. Abid MR, Guo S, Minami T, Spokes KC, Ueki K, Skurk C, Walsh K, Aird WC: Vascular endothelial growth factor activates PI3K/Akt/forkhead signaling in endothelial cells. Arterioscler Thromb Vasc Biol 2004, 24(2):294-300.

23. A-w S, Wang X-b L, F-x ZM-m, X-q K, K-j C: Ginsenoside Rg1 promotes endothelial progenitor cell migration and proliferation. Acta Pharmacol Sin 2009, 30(3):299-306.

24. Liang J, Slingerland JM: Multiple roles of the PI3K/PKB (Akt) pathway in cell cycle progression. Cell cycle 2003, 2(4):336-342.

25. Leung KW, Pon YL, Wong RN, Wong AS: Ginsenoside-Rg1 induces vascular endothelial growth factor expression through the glucocorticoid receptor-related phosphatidylinositol 3-kinase/Akt and $\beta$-catenin/T-cell factor-dependent pathway in human endothelial cells. J Biol Chem 2006, 281(47):36280-36288.

26. Iwanaga $K$, Yabuta T, Kakemi M, Morimoto $K$, Tabata $Y$, Ikada $Y$ : Usefulness of microspheres composed of gelatin with various cross-linking density. J Microencapsul 2003, 20(6):767-776.

27. Park YJ, Lee YM, Lee JY, Seol YJ, Chung CP, Lee SJ: Controlled release of platelet-derived growth factor-BB from chondroitin sulfate-chitosan sponge for guided bone regeneration. J Control Release 2000, 67(2):385-394.

28. Popovich DG, Kitts DD: Structure-function relationship exists for ginsenosides in reducing cell proliferation and inducing apoptosis in the human leukemia (THP-1) cell line. Arch Biochem Biophys 2002, 406(1):1-8.

29. Tongay S, Dag S, Durgun E, Senger R, Ciraci S: Atomic and electronic structure of carbon strings. J Phys Condens Matter 2005, 17(25):3823-3837.

doi:10.1186/1475-925X-12-134

Cite this article as: Zheng et al: In vitro evaluation of Panax notoginseng $\mathrm{Rg} 1$ released from collagen/

chitosan-gelatin microsphere scaffolds for angiogenesis. BioMedical Engineering OnLine 2013 12:134.

\section{Submit your next manuscript to BioMed Central and take full advantage of:}

- Convenient online submission

- Thorough peer review

- No space constraints or color figure charges

- Immediate publication on acceptance

- Inclusion in PubMed, CAS, Scopus and Google Scholar

- Research which is freely available for redistribution

Submit your manuscript at www.biomedcentral.com/submit 